\title{
Composição da comunidade bacteriana aérea de Santarém, Pará: influência de aves
}

O ar livre é uma mistura que inclui poluentes biológicos, com potencial efeito sobre a saúde das pessoas e possível problema de saúde pública. Esta pesquisa teve por objetivo identificar a comunidade bacteriana do ar de áreas urbanas em Santarém-PA, e correlacionar a diversidade de micro-organismos com a presença de aves. Entre agosto de 2017 a maio de 2018, pela técnica de sedimentação espontânea placas contendo PCA foram expostas em dez pontos em área urbana de Santarém. No Laboratório de Bacteriologia da Universidade Federal do Oeste do Pará, as placas foram incubadas a $35^{\circ} \mathrm{C}$ por tempo máximo de 48 horas, nesse período foram realizadas contagens de bactérias seguido de isolamento e purificação das colônias. O processo de purificação se deu em meio TSA, seguida de teste morfotintorial pela coloração de Gram, e série bioquímica para identificação ao menor nível taxonômico possível. Entre os gêneros encontrados, destaque se deu para Staphylococcus spp., Mycobacterium spp. e Lactobacillus spp. Os resultados, mostraram influência da presença das garças sobre a abundância e riqueza de bactérias, exceto no ponto controle, por ser uma área arborizada e não haver presença das aves, houve baixo crescimento bacteriano.

Palavras-chave: Amazônia; Aves; Bactérias.

\section{Composition of the aerial bacterial community of Santarém, Pará: influence of birds}

\begin{abstract}
The open air is a mixture that includes biological pollutants, with a potential effect on people's health and a possible public health problem. This research aimed to identify the bacterial community of urban areas in Santarém-PA, and to correlate a diversity of microorganisms with the presence of birds. Between August 2017 and May 2018, by the technique of spontaneous sedimentation, plates containing PCA were exposed at ten points in the urban area of Santarém. At the Bacteriology Laboratory of the Federal University of Western Pará, plaques were incubated at $35^{\circ} \mathrm{C}$ for a maximum of 48 hours, during which bacteria counts were initiated by isolation and purification of colonies. The purification process took place in the TSA medium, after the morphotintorial test by Gram stain, and the biochemical series for identification at the lowest possible taxonomic level. Among the genera found, we highlight Staphylococcus spp., Mycobacterium spp. and Lactobacillus spp. The results, the influence of the presence of claws on the economy and the richness of bacteria, except for the control point, as it is a wooded area and there is no presence of birds, had low bacterial growth
\end{abstract}

Keywords: Amazon; Birds; Bacteria.

Topic: Microbiologia Agrícola e Ambiental

Reviewed anonymously in the process of blind peer.
Received: 01/12/2020

Approved: 23/12/2020
Rídel Rodrigo Silva Fernandes (iD)

Universidade Federal do Oeste do Pará, Brasil

http://lattes.cnpq.br/3506458183243460

http://orcid.org/0000-0002-8181-4625

ridelrodrigo1995@gmail.com

Suellen Caroline Barbosa Neves (iD)

Universidade Federal do Oeste do Pará, Brasil

http://lattes.cnpq.br/4688488439787981

http://orcid.org/0000-0002-0221-6855

scambiente@hotmail.com

Andresa Krislany Ferreira (D)

Universidade Federal do Oeste do Pará, Brasi

http://lattes.cnpq.br/2342554663780207

http://orcid.org/0000-0001-5413-3077

andresa.krislany@yahoo.com.br

\section{Andreza da Silva Peixoto (iD \\ Universidade Federal do Oeste do Pará, Brasil \\ http://lattes.cnpq.br/2222990032367605 \\ http://orcid.org/0000-0003-0740-8386 \\ andrezapeixoto9@gmail.com}

Graciene do Socorro Taveira Fernandes (iD

Universidade Federal do Oeste do Pará, Brasil

http://lattes.cnpq.br/9121021285937589

http://orcid.org/0000-0002-2710-4251

gracienefernandes@hotmail.com
Referencing this:

FERNANDES, R. R. S.; NEVES, S. C. B.; FERREIRA, A. K.; PEIXOTO, A. S.; FERNANDES, G. S. T.. Composição da comunidade bacteriana aérea de Santarém, Pará: influência de aves. Revista Ibero Americana de Ciências Ambientais, v.11, n.7, p.170-178, 2020. DOI: http://doi.org/10.6008/CBPC2179-6858.2020.007.0016 


\section{INTRODUÇÃO}

O desenvolvimento econômico acelerado aliado ao crescimento populacional requer grande quantidade de recursos para sustentar as atividades da sociedade atual. Como resultado disso, vários tipos de poluição, incluindo a atmosférica, se intensificam (LEUNG, 2015).

$\mathrm{O}$ ar e toda diversidade de micro-organismos contida nele se conecta com os demais ecossistemas terrestres e aquáticos. Uma vez depositados na superfície, os micro-organismos são responsáveis por etapas importantes em todos os principais ciclos de nutrientes, mas muito pouco é conhecido sobre os mecanismos que controlam os efeitos microbianos atmosféricos dispersos para os ecossistemas (SPRING et al., 2018). O campo da aerobiologia é relativamente novo, carente de estudos, especialmente na Amazônia (WOMACK et al., 2010). Existem milhares de micro-organismos em um litro de ar, estão presentes em toda a atmosfera, e até mesmo na estratosfera. As comunidades microbianas variam com os eventos meteorológicos e atividade humana e alguns micro-organismos provavelmente se mantém ativos no ar (ZHEN et al., 2017). No entanto, ainda existem muitas perguntas que não foram respondidas sobre quais micro-organismos estão presentes e sobre a sua ecologia (BARBERÁN et al., 2015).

A qualidade do ar livre (outdoor) é um dos mais significativos fatores que afetam o bem-estar das pessoas e saúde do ecossistema (JACOB et al., 2016). Os poluentes do ar livre incluem vários compostos químicos, bem como vários poluentes biológicos, especialmente bactérias e fungos (JACOB et al., 2016). Segundo Kembel et al. (2012) cerca de $10^{6}$ células bacterianas por $\mathrm{m}^{3}$ estão presentes no ar externo e interno, portanto o potencial efeito sobre a população circulante no ambiente existe.

O ar livre é considerado um vetor de disseminação de micro-organismos, podendo conter agentes infecciosos e com potencial risco para a saúde pública. Mesmo que a maioria das infecções hospitalares estejam relacionadas à procedimentos cirúrgicos e terapêuticos, essas infecções também podem ser veiculadas pelo ar livre e devem ser consideradas (MURRAY et al., 2006). Entre as doenças que podem ser ocasionadas por bactérias e fungos presentes no ar livre destacam-se várias respiratórias ou condições como asma, bronquite, pneumonia, doença pulmonar obstrutiva crônica (DPOC), alergias sazonais, entre outras (BOWERS et al., 2011).

A microrregião de Santarém, localizada na região Oeste do Estado do Pará, um dos principais cartões postais do estado e do País. Caracteriza-se por apresentar um ecossistema diversificado e ainda bastante inexplorado, sendo que entre os principais atrativos turísticos destacam-se a cultura gastronômica, indumentárias e belezas naturais (COSTA, 2014). Atualmente, a presença de garças das espécies Ardea alba e Egretta thula tem sido constante em pontos específicos na área urbana de Santarém. Essas são aves que vivem aos bandos, frequentam rios, lagoas, pântanos, praias marítimas ou manguezais e a dieta desses animais inclui peixes, crustáceos, anfíbios, moluscos e pequenas aves (HANCOCK et al., 1978).

Este trabalho teve por objetivo avaliar a presença e abundância de bactérias heterotróficas totais cultiváveis presentes na microbiota do ar e se existe influência entre abundância e a presença de garças. 


\section{MATERIAIS E MÉTODOS}

No presente estudo foram escolhidos 3 pontos centrais e dois pontos adjacentes, e 1 ponto controle em área urbana de Santarém, Pará, totalizando 10 pontos amostrais (Figura 1).

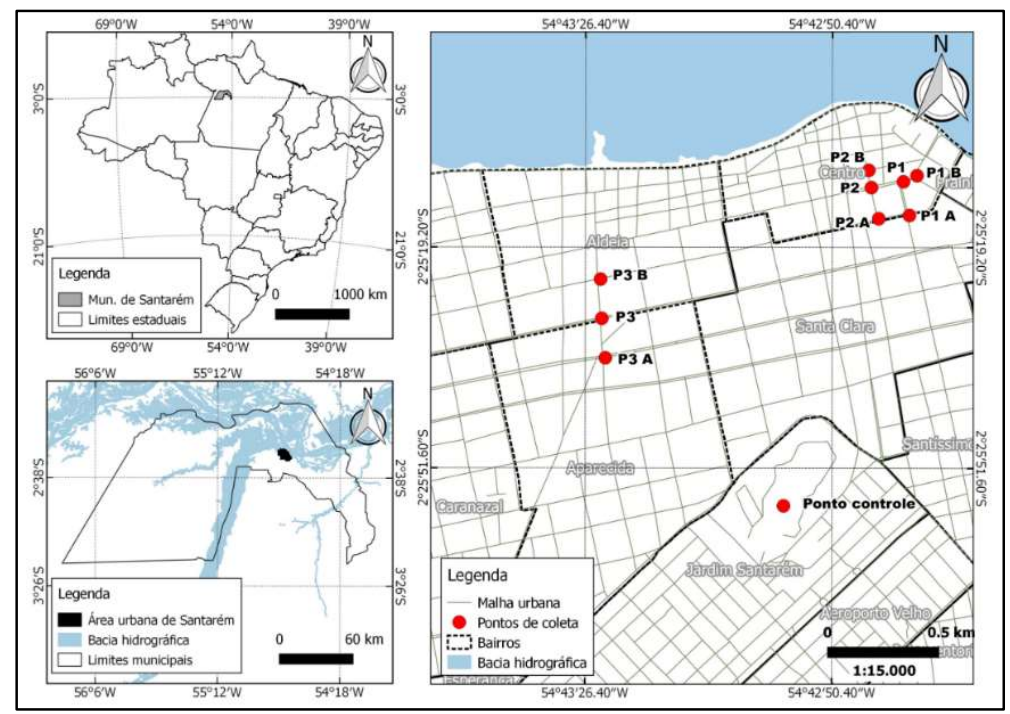

Figura 1: Mapa com os pontos de coleta da comunidade bacteriana na área urbana de Santarém, Pará.

Foram realizadas quatro coletas, em dois períodos, primeiro entre os meses de agosto e posteriormente, em novembro de 2017 e fevereiro e maio de 2018, nos 3 pontos amostrais localizados na área urbana de Santarém, onde são avistadas a presença das aves. De cada ponto central, foram selecionados dois pontos adjacentes ( $\mathrm{A}$ e B) e ponto controle (sem a presença das aves) P4.

Para a coleta das amostras, foi utilizada a técnica de exposição pelo método de sedimentação espontânea, com duplicata, em placas de Petri, contendo o meio Plate Count Ágar (PCA-Difco ${ }^{\circledR}$ ). As placas foram expostas nos pontos amostrais (Figura 1) por 15 minutos a uma altura aproximada de 1 metro suportadas por bandejas.

Após a exposição, no Laboratório de Bacteriologia (Labac) da UFOPA, as placas foram incubadas em estufa à $37^{\circ} \mathrm{C}$ por 48 horas com observação a cada 24 horas. Findo o período de cultivo, foram realizadas a Contagem Padrão em Placas (CPP), o resultado foi expresso em UFC/m3, e o isolamento das colônias viáveis cultiváveis para identificação ao menor nível taxonômico possível.

Após o isolamento, a purificação bacteriana se deu em meio Ágar Triptona Soja (TSA-BD ${ }^{\circledR}$ ) com incubação a $35{ }^{\circ} \mathrm{C}$ por $24 \mathrm{~h}$, novamente foi realizado teste tintorial (coloração de Gram), microscopia, descrição de morfologia, feito cultivo em meios específicos para Gram positivo e negativo e série bioquímica, tais como: anaerobiose, catalase, fermentação em Ágar Manitol, hemólise, hidrólise de esculina, coloração de Ziehl-Neelsen, teste de oxidase e fermentação de glicose, para identificação ao menor nível taxonômico de acordo com Staley et al. (2005).

Após a identificação, as bactérias foram isoladas e mantidas em tubos de ensaio contendo TSA e armazenadas na coleção bacteriológica do Labac. Após análises, os dados foram tabulados e feita a estatística, utilizando o teste $T$, para avaliar se a presença das aves afeta o quantitativo de bactérias heterotróficas e regressão para comparar as variáveis temperatura e umidade tem algum efeito no conjunto 
de dados obtidos.

\section{RESULTADOS E DISCUSSÃO}

Foram contadas 1.891 de colônias de bactérias heterotróficas, deste 224 isolados foram obtidos e identificados no período de coleta. O teste morfotintorial mostrou que $97 \%$ tem padrão Gram positivo (64\% bacilos e $36 \%$ cocos) e $3 \%$ Gram negativo ( $79 \%$ bacilos e $21 \%$ cocos). Não houve crescimento significativo ( $<25$ colônias) no ponto controle em nenhuma das coletas, na quarta coleta nos pontos P2A e P1B, e o ponto P1B na terceira coleta.

Em termo quantitativos os pontos P3 $(19,9 \%)$ e P2 (19,5\%), foram os que apresentaram maior número de UFC/m3. Entretanto, os resultados por ponto de amostragem mostraram que o ponto P3 teve maior número de bactérias heterotróficas na primeira e terceira coletam, o ponto $\mathrm{P} 2$, na segunda, e o ponto P1 na quarta coleta (Figura 2).

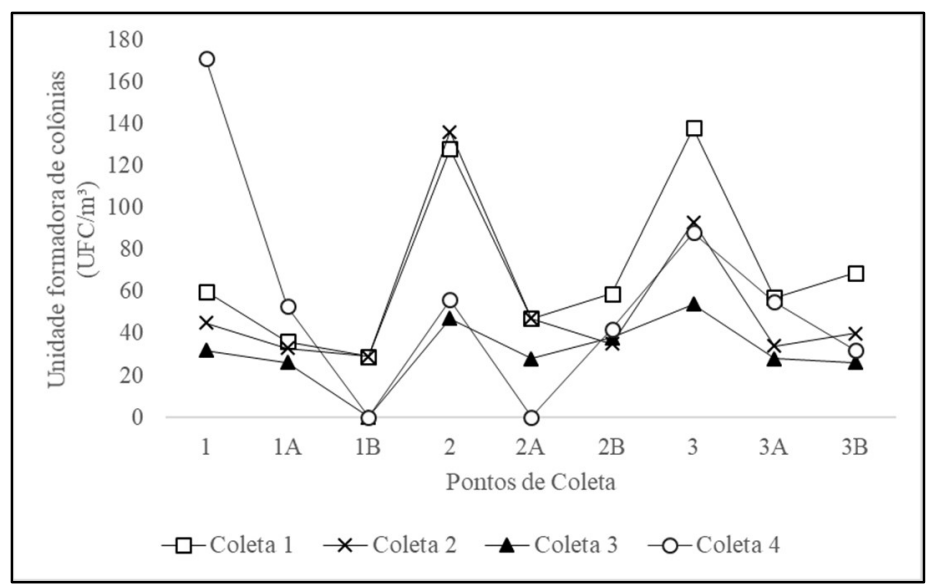

Figura 2: Média das Unidades Formadoras de Colônias de bactérias heterotróficas $\left(\mathrm{UFC} / \mathrm{m}^{3}\right)$, por ponto de coleta do ar em área urbana de Santarém, Pará, Brasil.

De acordo com o teste $\mathrm{T}$, a presença de garças, causa elevação no número de bactérias presentes na comunidade bacteriana heterotrófica do ar da área urbana de Santarém $(p=0,005)$.

Os testes bioquímicos dos 224 isolados bacterianos analisados, mostraram que os gêneros com maior frequência foram: Lactobacillus spp., Mycobacterium spp., Staphylococcus spp., Corynebacterium spp., Streptococcus spp. (Tabela 1).

Tabela 1: Distribuição dos gêneros bacterianos isoladas do ar de área urbana de Santarém (Pará, Brasil) por ponto de coleta com seus respectivos percentuais.

\begin{tabular}{llll|lll|lllll}
\hline \multirow{2}{*}{ Gênero } & \multicolumn{1}{l}{ Pontos } & \multicolumn{1}{l}{ Total } \\
\cline { 2 - 12 } & P1 & P1A & P1B & P2 & P2A & P2B & P3 & P3A & P3B & n & \% \\
\hline Lactobacillus spp. & 4 & 6 & 5 & 8 & 3 & 3 & 7 & 6 & 9 & 51 & 22,8 \\
Mycobacterium spp. & 4 & 5 & 3 & 9 & 1 & 7 & 9 & 3 & 6 & 47 & 20,9 \\
Staphylococcus spp. & 4 & 5 & 2 & 10 & 2 & 6 & 10 & 4 & 3 & 46 & 20,5 \\
Corynebacterium spp. & 3 & 1 & 1 & 3 & 3 & 3 & 4 & 3 & 4 & 25 & 11,2 \\
Streptococcus spp. & 3 & 1 & 1 & 4 & 0 & 3 & 3 & 1 & 1 & 17 & 7,6 \\
Clostridium spp. & 2 & 1 & 1 & 3 & 1 & 2 & 3 & 2 & 0 & 15 & 6,7 \\
Enterococcus spp. & 2 & 2 & 0 & 2 & 0 & 1 & 5 & 0 & 2 & 14 & 6,2 \\
Bacillus spp. & 1 & 1 & 0 & 0 & 0 & 1 & 2 & 1 & 0 & 6 & 2,7 \\
Micrococcus spp. & 1 & 0 & 0 & 0 & 0 & 1 & 1 & 0 & 0 & 3 & 1,3 \\
\hline Total de isolados & 24 & 22 & 13 & 39 & 10 & 27 & 44 & 20 & 25 & 224 \\
\hline \% de isolados & 10,7 & 9,8 & 5,8 & 17,4 & 4,5 & 12,1 & 19,6 & 8,9 & 11,2 & \\
\hline
\end{tabular}


Microorganismos de várias fontes, contribuem para uma carga microbiana uniforme e diluída em uma determinada parcela de ar, e podem estar relacionados ao transporte aéreo do solo e outros reservatórios como função das condições ambientais (SPRING et al., 2018). Contudo, ao encontrar uma fonte de partículas transportadas pelo ar, é esperada que a concentração local de micro-organismos seja maior e diferente do conjunto de micro-organismos que se originaram em locais mais distantes (LYMPEROPOULOU et al., 2016). É possível que o fato de o ponto controle por ser uma área urbana, mas arborizada, tenha influenciado na população inferior a 25 UFC's conforme também foi evidenciado na pesquisa realizada por Mhuireach et al. (2016).

Também não apresentaram crescimento bacteriano significativo os pontos P1B na terceira (fevereiro de 2018) e quarta (maio de 2018) coletas, e P2A na quarta coleta. Segundo Bragoszewska et al. (2017), parâmetros ambientais e climáticos, como temperatura, radiação UV, umidade relativa, velocidade do vento, entre outros têm grande interferência na população de bactérias do ar livre em áreas urbanas e entre estas variáveis que tem maior efeito são a temperatura e radiação UV.

Conforme mostrado na tabela 1, dos nove gêneros bacterianos identificados, os três mais expressivos foram Lactobacillus spp. (22,8\%), seguido de Mycobacterium spp. (20,9\%) e Staphylococcus spp. (20,5\%). Os pontos que tiveram maior abundância de Lactobacillus spp. foi o ponto P3B, Mycobacterium spp. e Staphylococcus spp. foram igualmente mais frequentes nos pontos P2 e P3 (Tabela 1).

O gênero Lactobacillus é uma bactéria Gram-positiva, não esporulada, catalase negativa, e aerotolerante (STALEY et al., 2005), sendo composto por mais de 60 espécies habitam como comensais, os tratos respiratório e digestório dos animais e vagina humana (BARROS et al., 2009). Nossos resultados refletem que o número expressivo deste gênero nas amostras analisadas, se justificam pela acentuada presença das fezes das aves residentes evidenciadas nos pontos de coleta.

Barberán et al. (2015), mostraram que este gênero bacteriano foi o mais abundante em amostras de ar indoor. Outros autores corroboram estes achados e reforçam que as bactérias deste gênero são mais frequentemente detectadas em amostras de ar interior, especialmente residências onde hajam crianças ou com grande número de pessoas, nesses casos sendo atribuído as bactérias desse gênero um fator protetivo contra infecções e alergias, que é explicado pelo fato de que Lactobacillus spp. é a bactéria mais abundante no microbioma do corpo humano (HANSON et al., 2016)

A maioria das bactérias desse gênero têm aplicação na indústria ou no tratamento de problemas de saúde humana (MESSAOUDI et al., 2011; KADOOKA et al., 2010).

As bactérias representantes do gênero Staphylococcus estão entre as de destaque em amostras de ar de residências em que há presença de animais domésticos, sendo-lhe atribuída o papel de desencadeador de crises alérgicas e asma em crianças (DANNEMILLER et al., 2017). Staphylococcus tem sido identificado pela abundancia em várias pesquisas com amostras de ar de ambientes internos (residências, hospitais, escritórios e prédios), e na pesquisa realizada por Moschandreas et al. (2003), estas bactérias representaram um terço do total de isolados identificados em residências de Chicago (EUA) (NADIMPALLI et al., 2018; HANSON et al., 2016). 
A pesquisa realizada por Makut et al. (2014), com amostra do ar livre em Keffi, na Nigéria, encontraram maior abundância da bactéria Staphylococcus aureus. A S. aureus pode ser comensal ou se comportar como patógeno, causando infecções oportunistas de tecidos moles, mas também infecções de sangue, osteomielite, septicemia artrite, endocardite, pneumonia e sepse (SANTOS et al., 2007).

A alta frequência desta espécie tanto em amostras de ar de ambiente externo quanto interno, tem sido uma preocupação de saúde pública global, uma vez que essa bactéria adquire resistência a muitos antibióticos simultaneamente, especialmente no caso de $S$. aureus resistente à meticilina (MRSA) (DAVIS et al., 2012).

Entre os três gêneros bacterianos identificados no ar de área urbana de Santarém, podemos salientar a presença de Mycobacterium em todos os pontos de amostragem (Tabela 1). 0 gênero Mycobacterium abriga bactérias patogênicas que podem causar graves doenças ao homem, como a $M$. tuberculosis, por exemplo (GAGNEUX, 2018). A microbiota do ar, tem mostrado um aumento na incidência mundial e prevalência de doenças causadas por micobactérias não tuberculosas (MNT), especialmente as doenças do complexo Mycobacterium avium (MAC), ressaltando que as pesquisas se basearam em amostras de ar (NISHIUCHI et al., 2017)

De acordo com Hruska et al. (2012) as micobactérias isoladas no ar estão associadas a poeira ou partículas originárias da água ou do solo. As espécies e concentração de micobactérias no ar e muitos fatores, como o tempo de exposição, quantidade e virulência do patógeno, colocam pessoas em perigo de infecção. O local desta pesquisa é público e com grande circulação de pessoas em vários níveis de condição imune, é importante que sejam tomadas ações de monitoramento e para auxiliar políticas públicas de saúde da população.

É importante destacar, apesar da baixa incidência, da presença em oito dos dez pontos amostrais, de bactérias do gênero Clostridium. As bactérias pertencentes ao gênero Clostridium são Gram-positivas, aerotolerantes, esporogênicas e a maioria é patogênicas (GOMES et al., 2013). Entre as espécies patogênicas podemos citar C. tetani, C. botulinum, C. perfringens, e C. difficile (COHEN et al., 2010; RAGAZANI et al., 2008; LOBATO et al., 2007; VITTORI et al., 2007).

A presença de Clostridium spp. é bastante pesquisada em ambiente hospitalar e espaços públicos fechados, porém em ambiente exterior é carente de informações (KUNWAR et al., 2019; ARIZA-HEREDIA et al., 2018; HUESCA-ESPITIA et al., 2018). Nesse sentido, há que se fazer alerta a respeito da presença deste patógeno para garantir que sejam tomadas medidas prevencionistas e controle de infecções dos transeuntes.

A permanência da microbiota aérea em determinada área está sujeita a variações na concentração e distribuição de micro-organismos cultiváveis causada por fatores que são muito complexos e incluem parâmetros meteorológicos, condições climáticas, força do vento e ambiente geográfico, além variar de acordo com as diferentes estações do ano (GUSAREVA et al., 2019; CAVICCHIOLI et al., 2019; BRAGOSZEWSKA et al., 2017). Fatores mecânicos, como chuva ou vento, também afetam a manutenção do material em suspensão, favorecendo a sua sedimentação ou a sua dispersão (GRIFFIN, 2007). Nossos resultados, diferem das demais pesquisas, pois não revelaram relação das variáveis temperatura e umidade com a comunidade 
bacteriana amostrada.

A respeito do ponto controle não ter apresentado crescimento bacteriano significativo (inferior a 25 UFC's) e, portanto, não ter sido isolado cepas, deve-se ao fato de este local ser uma área arborizada e não haver presença das garças.

Mhuireach et al. (2016) evidenciaram em sua pesquisa que áreas urbanas onde há arborização tem a composição da microbiota bacteriana influenciada pela vegetação, apesar de os autores não conseguirem correlacionar o tipo de vegetação com a influência exercida sobre os grupos taxonômicos identificados.

As garças estiveram presentes nos pontos amostrais, exceto o ponto controle, durante todo período de coleta, quando não eram avistadas a permanência dos animais, a presença destas foi evidenciada pelas fezes, nas proximidades das árvores nos pontos amostrais. Também foi constatado um fluxo intenso de veículos e pessoas em todos os pontos durante o período de coletas, o que pode favorecer a dispersão desses dos micro-organismos.

Há poucas pesquisas que tenham como objetivo o estudo da qualidade do ar livre nas cidades da Amazônia, o que acaba por dificultar uma discussão ou mesmo comparação sobre os aspectos da diversidade e sobre os micro-organismos identificados. Esta pesquisa mostrou que a presença das aves contribuiu para o aumento do número de bactérias heterotróficas totais cultiváveis presentes no ar de áreas urbanas de Santarém, Pará.

\section{CONCLUSÕES}

A presença de garças afeta o número de bactérias presentes no ar nas áreas de estudo, entre os pontos de amostragem. Vários gêneros de bactérias potencialmente patogênicas, principalmente nos pontos onde foram evidenciadas presença das aves. Foi possível concluir que áreas urbanas com arborização tem efeito redutor na população bacteriana heterotrófica cultivável.

Necessário realizar monitoramento para ampliar o conhecimento sobre o significado desta via na disseminação, uma vez que no ar livre foram identificados micro-organismos patogênicos e pode colocar em risco a manutenção da saúde humana.

AGRADECIMENTOS: A UFOPA pela concessão da bolsa e espaço físico e ao Laboratório de Bacteriologia da Universidade Federal do Oeste do Pará.

\section{REFERÊNCIAS}

ARIZA-HEREDIA, E. J.; CHEMALY, R. F.. Update on infection control practices in cancer hospitals. CA: a cancer journal for clinicians, v.68, n.5, p.340-355, 2018. DOI:

https://doi.org/10.3322/caac.21462

BARBERÁN, A.; LADAU, J.; LEFF, J. W.; POLLARD, K. S.; MENNINGER, H. L.; DUNN, R. R.; FIERER, N.. Continentalscale distributions of dust-associated bacteria and fungi. Proceedings of the National Academy of Sciences, n.112, v.18, p.5756-5761, 2015. DOI: https://doi.org/10.1073/pnas.1420815112
BARROS, M. R.; ANDREATTI FILHO, R. L.; OLIVEIRA, D. E.; LIMA, E. T.; CROCCI, A. J.. Comparação entre método bioquímico e reação em cadeia de polimerase para identificação de Lactobacillus spp., isolados de aves. Arquivo Brasileiro de Medicina Veterinária e Zootecnia, v.61, n.2, p.319-325, 2009. DOI: http://dx.doi.org/10.1590/S0102$\underline{09352009000200006}$

BOWERS, R.; SULLIVAN, A.; COSTELLO, E.; COLLETT, J.; KNIGHT, R.; FIERER, N.. Sources of bacteria in outdoor air 
across cities in the Midwestern United States. Applied and Environmental Microbiology, v.77, p.6350-6356, 2011. DOI: https://doi.org/10.1128/AEM.05498-11

BRAGOSZEWSKA, E.; MAINKA, A.; PASTUSZKA, J. S. Concentration and size distribution of culturable bacteria in ambient air during spring and winter in gliwice: A typical urban area. Atmosphere, v.239, n.8, p.1-13, 2017. DOI: https://doi.org/10.3390/atmos8120239

CAVICCHIOLI, R.; RIPPLE, W. J.; TIMMIS, K. N.; AZAM, F.; BAKKEN, L. R.; BAYLIS, M.; BEHRENFELD, M. J.; BOETIUS, A.; BOYD, P. W.; CLASSEN, A. T.; CROWTHER, T. W.; DANOVARO, R.; FOREMAN, C. M.; HUISMAN, J.; HUTCHINS, D. A.; JANSSON, J. K.; KARL, D. M.; KOSKELLA, B.; WELCH, D. B. M.; MARTINY, J. B. H.; MORAN, M. A.; ORPHAN, V. J.; REAY, D. S.; REMAIS, J. V.; RICH, V. I.; SINGH, B. K.; STEIN, L. Y.; STEWART, F. J.; SULLIVAN, M. B.; VAN OPPEN, M. J. H.; WEAVER, S. C.; WEBB, E. A.; WEBSTER, N. S. Scientists warning to humanity: microorganisms and climate change. Nature Reviews Microbiology, v.17, n.9, p.569-586, 2019. DOI: https://doi.org/10.1038/s41579-019-0222-5

COHEN, S. H.; GERDING, D. N.; JOHNSON, S.; KELLY, C. P.; LOO, V. G.; MCDONALD, L. C.; PEPIN, J.; WILCOX, M. H.. Clinical practice guidelines for Clostridium difficile infection in adults: 2010 update by the society for healthcare epidemiology of america (shea) and the infectious diseases society of america (idsa). Infection Control And Hospital Epidemiology, v.31, n.5, p.431-455, 2010. DOI: https://doi.org/10.1086/651706

COSTA, G. G.. As cidades amazônicas na América portuguesa. EXAMÃPAKU, v.7, n.2, p.18-40, 2014. DOI: http://dx.doi.org/10.18227/1983-9065ex.v7i2.2408

DANNEMILLER, K. C.; WESCHLER, C. J.; PECCIA, J.. Fungal and bacterial growth in floor dust at elevated relative humidity levels. Indoor Air, v.27, n.2, p.354-363, 2017. DOI: https://doi.org/10.1111/ina.12313

DAVIS, M. F.; IVERSON, S. A.; BARON, P.; VASSE, A.; SILBERGELD, E. K.; LAUTENBACH, E.; MORRIS, D. O. Household transmission of meticillin: resistant Staphylococcus aureus and other staphylococci. The Lancet Infectious Diseases, v.12, n.9, p.703-716, 2012. DOI: https://doi.org/10.1016/S1473-3099(12)70156-1

GAGNEUX, S.. Ecology and evolution of Mycobacterium tuberculosis. Nature Reviews Microbiology, v.16, n.4, p.202, 2018. DOI: https://doi.org/10.1038/nrmicro.2018.8

GOMES, M. J.; BACILAR, H.. Gênero Clostridium spp. Porto Alegre: Favet-Ufrgs, 2013.

GRIFFIN, D. W.. Atmospheric movement of microorganisms in clouds of desert dust and implications for human health. Clinical Microbiological Reviews, v.20, p.459-477, 2007. DOI: https://doi.org/10.1128/CMR.00039-06

GUSAREVA, E. S.; ACERBI, E.; LAU, K. J. X.; LUHUNG, I.; PREMKRISHNAN, B. N. V.; KOLUNDZIJA, S.; PURBOJATI, R. W.; WONG, A.; HOUGHTON, J. N. I.; MILLER, D.; GAULTIER, N. E.; HEINLE, C. E.; CLARE, M. E.; VETTATH, V. K.; KEE, C.; LIM, S. B. Y.; CHÉNARD, C.; PHUNGA, W. J.; KUSHWAHA, K. K.; NEE, A. P.; PUTRA, A.; PANICKER, D.; YANQING, K.; HWEE, Y. Z.; LOHARA, S. R.; KUWATA, M.; KIMA, H. L.; YANG, L.;
UCHIDA, A.; DRAUTZ-MOSES, D. I.; JUNQUEIRA, A. C. M.; SCHUSTERA, S. C.. Microbial communities in the tropical air ecosystem follow a precise diel cycle. Proceedings of the National Academy of Sciences, v.116, n.46, p.23299-23308, 2019. DOI: https://doi.org/10.1073/pnas.1908493116

HANCOCK, J.; ELLIOT, H.. The Herons of the World. London Editions. 1978.

HANSON, B.; ZHOU, Y.; BAUTISTA, E.J.; URCH, B.; SPECK, M.; SILVERMAN, F.; MUILENBERG, M.; PHIPATANAKUL, W.; WEINSTOCK, G.; SODERGREN, E.; GOLDE, D. R.; SORDILLO, J. E.. Characterization of the bacterial and fungal microbiome in indoor dust and outdoor air samples: a pilot study. Environmental Science: Processes \& Impacts, v.18, n.6, p.713-724, 2016. DOI: https://doi.org/10.1039/C5EM00639B

HRUSKA, K.; KAEVSKA, M.. Mycobacteria in water, soil, plants and air: a review. Veterinarni Medicina, v.57, n.12, p.623-679, 2012

HUESCA-ESPITIA, L. D. C.; ASLANZADEH, J.; FEINN, R.; JOSEPH, G.; MURRAY, T. S.; SETLOW, P.. Deposition of bacteria and bacterial spores by bathroom hot-air hand dryers. Applied and Environmental Microbiology, v.84, n.8, p.e00044-18, 2018. DOI: https://doi.org/10.1128/AEM.00044-18

JACOB, J. H.; IRSHAID, F. I.; ALHALIB, M. A.. Estimation and identification of airborne bacteria and fungi in the outdoor atmosphere of Al-Mafraq area, Jordan. Jordan Journal Of Biological Sciences, v.9, n.1, p.3-10, 2016.

KADOOKA, Y.; SATO, A.; IMAIZUMI, K.; OGAWA, A.; IKUVAMA, K.; AKAI, Y.; OKANO, M.; KAGOSHIMA, M.; TSUCHIDA, T.. Regulation of abdominal adiposity by probiotics (Lactobacillus gasseri SBT2055) in adults with obese tendencies in a randomized controlled trial. European Journal Of Clinical Nutrition, v.64, p.636-643, 2010. DOI: https://doi.org/10.1038/ejcn.2010.19

KEMBEL, S. W.; JONES, E.; KLINE, J.; NORTHCUTT, D.; STENSON, J.; WOMACK, A. M.; BOHANNAN, B. J. M.; BROWN, G. Z.; GREEN, J. L.. Architectural design influences the diversity and structure of the built environment microbiome. The ISME journal, v.6, n.8, p.1469-1479, 2012. DOI: https://doi.org/10.1038/ismej.2011.211

KUNWAR, A.; TAMRAKAR, S.; POUDEL, S.; SHARMA, S.; PARAJULI, P.. Bacteriological Assessment of the Indoor Air of Different Hospitals of Kathmandu District. International Journal of Microbiology, v.2019, 2019. DOI: https://doi.org/10.1155/2019/5320807

LEUNG, D. Y. C.. Outdoor-indoor air pollution in urban environment: Challenges and opportunity. Frontiers In Environmental Science, v.69, n.2, p.1-7, 2015. DOI: https://doi.org/10.3389/fenvs.2014.00069

LYMPEROPOULOU, D. S.; ADAMS, R. I.; LINDOW, S. E.. Contribution of vegetation to the microbial composition of nearby outdoor air. Applied and Environmental Microbiology, v.82, p.3822-3833, 2016. DOI: https://doi.org/10.1128/AEM.00610-16

LOBATO, F. C. F.; SALVARANI, F. M.; ASSIS, R. A.; LIMA, E. H. M.; LIMA, C. G. R. D.; SILVA, R. O. S.; PIRES, P. S.. Avaliação 
da potência de vacinas contra Clostridium tetani comercializadas no Brasil. Ciência veterinária nos trópicos, v.10, p.74-78, 2007.

MESSAOUDI, M.; LALONDE, R.; VIOLLE, N.; JAVELOT, H.; DESOR, D.; NEJDI, A.; BISSON, J. F.; ROUGEOT, C.; PICHELIN, M.; CAZAUBIEL, M.; CAZAUBIEL, J. M.. Assessment of psychotropic-like properties of a probiotic formulation (Lactobacillus helveticus R0052 and Bifidobacterium longum R0175) in rats and human subjects. British Journal of Nutrition, v.105, p.755-764, 2011. DOI: https://doi.org/10.1017/S0007114510004319

MHUIREACH, G.; JOHNSON, B. R.; ALTRICHTER, A. E.; LADAU J.; MEADOW, J. F.; POLLARD, K. S.; GREEN, J. L.. Urban greenness influences airborne bacterial community composition. Science of the Total Environment, v. 571 , p.680-687, 2016. DOI: https://doi.org/10.1016/j.scitotenv.2016.07.037

MOSCHANDREAS, D. J.; PAGILLA, K. R.; STORINO, L. V.. Time and space uniformity of indoor bacteria concentrations in Chicago area residences. Aerosol Science \& Technology, v.37, n.11, p.899-906, 2003. DOI: https://doi.org/10.1080/02786820300935

MURRAY, P. R.; ROSENTHAL, K. S.; PFALLER, M. A.. Microbiología médica. Elsevier Health Sciences, 2017.

NADIMPALLI, M. L.; STEWART, J. R.; PIERCE, E.; PISANIC, N.; LOVE, D. C.; HALL, D.; LARSEN, J.; CARROLL, K. C.; TEKLE, T.; PERL, T. M.; HEANEY, C. D.. Face mask use and persistence of livestock-associated Staphylococcus aureus nasal carriage among industrial hog operation workers and household contacts, USA. Environmental Health Perspectives, v.126, n.12, p.127005, 2018. DOI: https://doi.org/10.1289/EHP3453

NISHIUCHI, Y.; IWAMOTO, T.; MARUYAMA, F.. Infection sources of a common non-tuberculous mycobacterial pathogen, Mycobacterium avium complex. Frontiers In Medicine, v.4, n.27, p.1-17, 2017. DOI: https://doi.org/10.3389/fmed.2017.00027

RAGAZANI, A. V. F.; SCHOKEN-ITURRINO, R. P.; GARCIA, G. R.; DELFINO, T. P. C.; POIATTI, M. L.; BERCHIELL, S. P..
Esporos de Clostridium botulinum em mel comercializado no estado de São Saulo e em outros estados brasileiros. Ciência Rural, v.38, n.2, p.396-399, 2008. DOI: https://doi.org/10.1590/S0103-84782008000200016

SANTOS, A. L.; SANTOS, D. O.; FREITAS, C. C.; FERREIRA, B. L. A.; AFONSO, I. F.; RODRIGUES, C. R.; CASTRO, H. C.. Staphylococcus aureus: visitando uma cepa de importância hospitalar. Jornal Brasileiro de Patologia e Medicina Laboratorial, v.43, n.6, p.413-423, 2007. DOI: https://doi.org/10.1590/S1676-24442007000600005

SPRING, A. M.; DOCHERTY, K. M.; DOMINGUE, K. D.; KERBER, T. V.; MOONEY, M. M.; LEMMER, K. M.. A method for collecting atmospheric microbial samples from set altitudes for use with next-generation sequencing techniques to characterize communities. Air, Soil and Water Research, v.11, p.1-12, 2018. DOI: https://doi.org/10.1177/1178622118788871

STALEY, J. T.; BRENNER, D. J.; GARRITY, G.; BOONE, D. R.; KRIEG, N. R.; VOS, P.; GOODFELLOW, M.; RAINEY, F. A.; GARRITY, G. M.; SCHLEIFER, K. H.. Bergey's manual of systematic bacteriology: Volume two: The Proteobacteria (Part C): The Alpha-, Beta-, Delta- and Epsilon Proteobacteria. Springer-Verlag: US., 2005.

VITTORI, J.; SCHOCKEN-ITURRINO, R. P.; TROVÓ, K. P.; RIBEIRO, C. A. M.; BARBOSA, G. G.; SOUZA, L. M.; PIGATTO, C. P.. Alphitobius diaperinus como veiculador de Clostridium perfringens em granjas avícolas do interior paulista. Ciência Rural, v.37, n.3, p.894-896, 2007. DOI: http://dx.doi.org/10.1590/S0103-84782007000300048

WOMACK, A. M.; BOHANNAN, B. J. M.; GREEN, J. L.. Biodiversity and biogeography of the atmosphere. Philosophical Transactions of the Royal Society B: Biological Sciences, v.365, p.3645-3653, 2010. DOI: https://doi.org/10.1098/rstb.2010.0283

ZHEN, Q.; DENG, Y.; WANG, Y.; WANG, X.; ZHANG, H.; SUN, X.; OUYANG, Z.. Meteorological factors had more impact on airborne bacterial communities than air pollutants. Science of the Total Environment, v.601, p.703-712, 2017. DOI: https://doi.org/10.1016/j.scitotenv.2017.05.049

A CBPC - Companhia Brasileira de Produção Científica (CNPJ: 11.221.422/0001-03) detém os direitos materiais desta publicação. Os direitos referem-se à publicação do trabalho em qualquer parte do mundo, incluindo os direitos às renovaç̃os, expansões e disseminacõos da contribuicão, bem como outros direitos subsidiários. Todos os trabalhos publicados eletronicamente poderão posteriormente ser publicados em coletâneas impressas sob coordenação da Sustenere Publishing, da Companhia Brasileira de Produção Científica e seus parceiros autorizados. Os (as) autores (as) preservam os direitos autorais, mas não têm permissão sob coordenção da Sustenere Publishing, da Companhia Brasileira de Produção cientica e seus parce 